\title{
An Anatomical study for localisation of Zygomatic branch of Facial nerve and Masseteric nerve - An aid to nerve coaptation for facial reanimation surgery: A cadaver based study in Eastern India
}

\author{
Ratnadeep Poddar, Alipta Bhattacharya, Iman Sinha, Asis Kumar Ghosal \\ Department of Anatomy, Institute of Postgraduate Medical Education and Research, Kolkata, West Bengal, India
}

Address for correspondence: Dr. Ratnadeep Poddar, Flat 2A, 229/1 Maharani Indira Devi Road, Parnasree, Behala, Kolkata - 700 060, West Bengal, India. E-mail: ratno.dp@gmail.com

\section{ABSTRACT}

Context: In cases of chronic facial palsy, where direct neurotisation is possible, ipsilateral masseteric nerve is a very suitable motor donor. We have tried to specifically locate the masseteric nerve for this purpose. Aims: Describing an approach of localisation and exposure of both the zygomatic branch of Facial nerve and the nerve to masseter, with respect to a soft tissue reference point over face. Settings and Design: Observational cross sectional study, conducted on 12 fresh cadavers. Subjects and Methods: A curved incision was given, passing about $0.5 \mathrm{cms}$ in front of the tragal cartilage. A reference point " $R$ " was pointed out. The zygomatic branch of facial nerve and masseteric nerve were dissected out and their specific locations were recorded from fixed reference points with help of copper wire and slide callipers. Statistical Analysis Used: Central Tendency measurements and Unpaired " $t$ " test. Results: Zygomatic branch of the Facial nerve was located within a small circular area of radius $1 \mathrm{~cm}$, the centre of which lies at a distance of 1.1 $\mathrm{cms}( \pm 0.4 \mathrm{~cm})$ in males and $0.2 \mathrm{~cm}( \pm 0.1 \mathrm{~cm})$ in females from the point, ' $R$ ', in a vertical (coronal) plane. The nerve to masseter was noted to lie within a circular area of $1 \mathrm{~cm}$ radius, the centre of which was at a distance of $2.5 \mathrm{cms}( \pm 0.4 \mathrm{~cm})$ and $1.7 \mathrm{cms}( \pm 0.2 \mathrm{~cm})$ from $R$, in male and female cadavers, respectively. Finally, Masseteric nerve's depth, from the masseteric surface was found to be $1 \mathrm{~cm}( \pm 0.1 \mathrm{~cm}$; male) and $0.8 \mathrm{~cm}( \pm 0.1 \mathrm{~cm}$; female). Conclusions: This novel approach can reduce the post operative cosmetic morbidity and per-operative complications of facial reanimation surgery.

\section{KEY WORDS}

Chronic facial palsy; masseteric nerve; zygomatic branch (of facial nerve)

\begin{tabular}{|l|l|}
\hline \multicolumn{2}{|c|}{ Access this article online } \\
\hline Quick Response Code: & Website: \\
\hline & www.ijps.org \\
\cline { 2 - 2 } & DOI: \\
\hline
\end{tabular}

This is an open access article distributed under the terms of the Creative Commons Attribution-NonCommercial-ShareAlike 3.0 License, which allows others to remix, tweak, and build upon the work non-commercially, as long as the author is credited and the new creations are licensed under the identical terms.

For reprints contact: reprints@medknow.com

How to cite this article: Poddar R, Bhattacharya A, Sinha I, Ghosal AK. An anatomical study for localisation of zygomatic branch of facial nerve and masseteric nerve - an aid to nerve coaptation for facial reanimation surgery: A cadaver based study in Eastern India. Indian J Plast Surg 2017;50:74-8. 


\section{INTRODUCTION}

acial nerve palsy has a worldwide annual incidence

4 of 30/100,000 persons. ${ }^{[1]}$ Considering the aetiology, idiopathic facial palsy has higher incidence in comparison to traumatic palsy in India. ${ }^{[2]}$ Considering the surgical options, the decision of choosing a specific surgical approach depends on the time of presentation of the patient. ${ }^{[3]}$ Reasonably good results were obtained by Anderl $(1973,1978)$ with multiple cross-facial nerve grafts in two stages. ${ }^{[4]}$ Previously, the 'Babysitting technique' with hypoglossal or masseteric or spinal accessory nerve was practiced during the interval between two stages of cross facial nerve grafting. ${ }^{[5]}$ Gradual experiences with

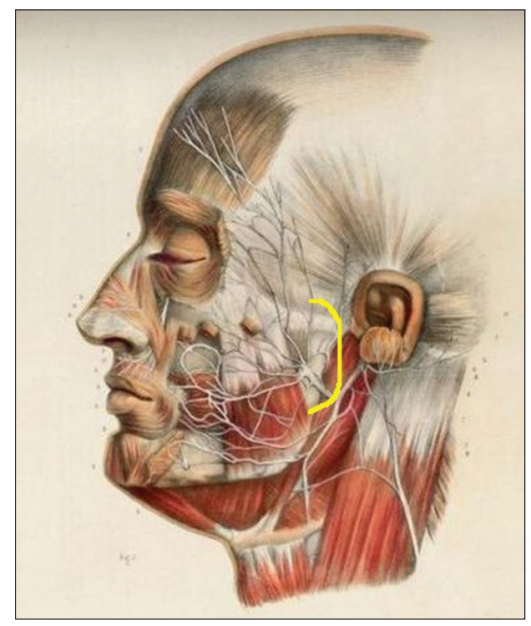

Figure 1: Schematic curved preauricular incision (yellow line) - edited with Microsoft Paint on primary internet source picture. Variations of the facial nerve (cranial nerve VII), shown in situ, in 2 numbered illustrations. Superficial dissection of the head and face to show nerves. Lateral views. https://www. pinterest.com/pin/379428337327818673

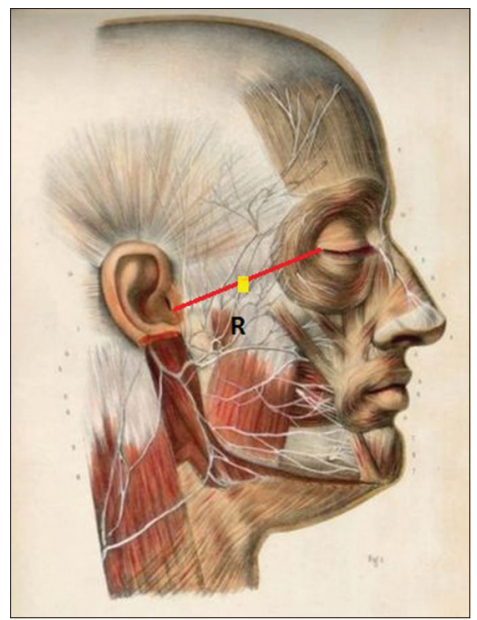

Figure 3: Reference point ( $r$ ) (yellow) - edited with Microsoft Paint on primary internet source picture. Variations of the facial nerve (cranial nerve VII), shown in situ, in 2 numbered illustrations. Superficial dissection of the head and face to show nerves. Lateral views. https://www.pinterest.com/ pin/379428337327818673 hypoglossal and spinal accessory nerves were not up to the expectation in respect to morbidity. ${ }^{[5,6]}$ However, primary nerve transfer using masseteric nerve was with the most favourable outcome in respect to both smile reconstruction and psychological rehabilitation of the patient. ${ }^{[7]}$ The 'subzygomatic triangle' ${ }^{\prime 8 \mid}$ approach is one of the procedures for pre-operative localisation of the masseteric nerve. The trainee surgeon might face challenges in the process of localisation of the nerve to masseter as studies pertaining to localisation of this nerve based on bony landmarks are limited, especially in the Indian subcontinent. Our study focuses on localisation and exposure of both the zygomatic branch of Facial nerve and the nerve to masseter with much ease as compared to the previous studies in this respect. This will be helpful during the period of training of plastic and reconstructive surgeons to perform the masseter facial nerve transfer with much ease.

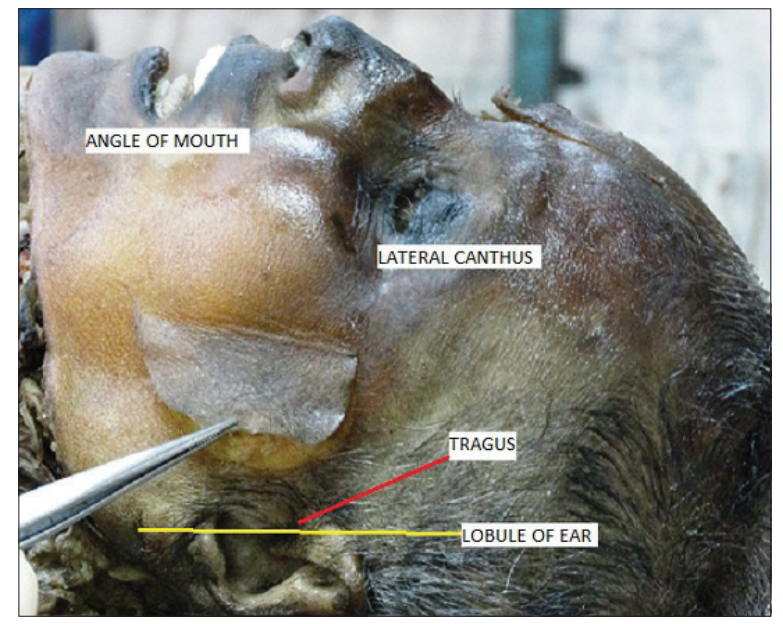

Figure 2: Skin incision (curved preauricular)

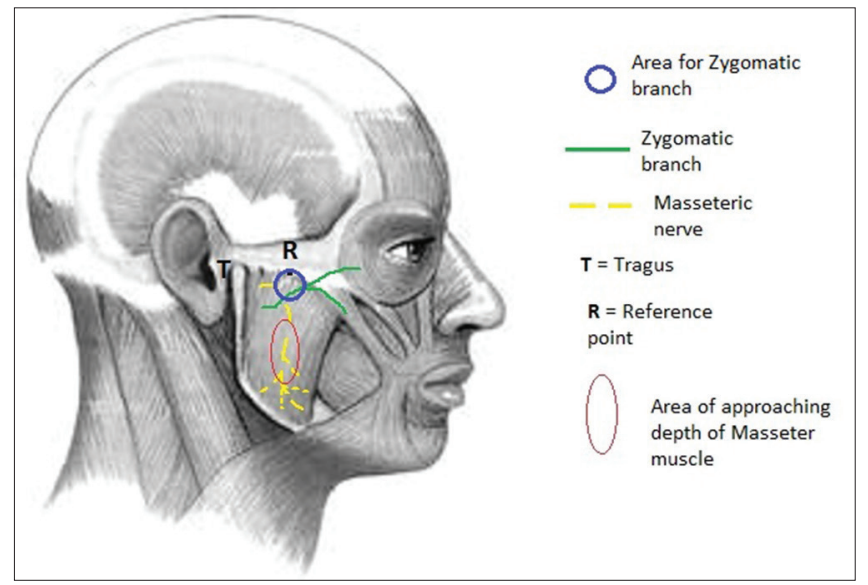

Figure 4: Schematic guidance to localisation of nerve to masseter and zygomatic branch of facial nerve. Edited with Microsoft Paint on primary internet source picture. https://www.pinterest.com/ pin/554576141589972856 


\section{SUBJECTS AND METHODS}

The study was carried out using 12 fresh cadavers (24 sides). Cadavers having scarring over the facial region or having deformities over the head and neck region were excluded from the study. Only adult cadavers were included in our study. The study population belonged to eastern India. The cadavers were placed in supine position with extended neck and under proper illumination, on the dissection table. The junction of medial two-third and lateral one-third of a line joining outer canthus of eye and tragal cartilage was marked with a skin marking pencil. A curved incision was given, passing about $0.5 \mathrm{~cm}$ in front of the tragal cartilage, extending from the above point up to another point, at the junction of medial two-third and lateral one-third of a line joining the lower margin of ear lobule with the angle of ipsilateral mouth [Figures 1 and 2]. On retracting the skin flap forwards, the superficial fascia

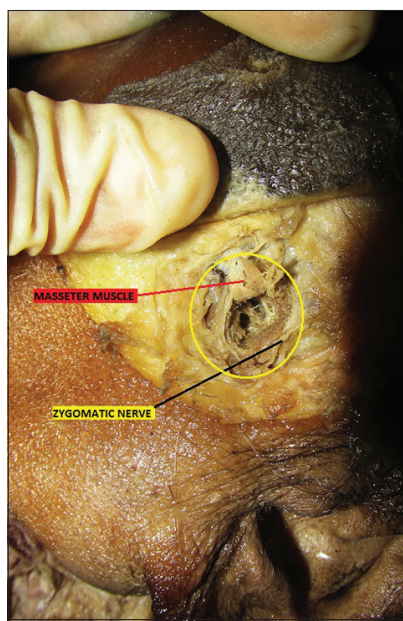

Figure 5: Operating Window for localisation of the concerned nerves (showed by yellow circle); superficial fibres of the masseter muscle are reflected forwards

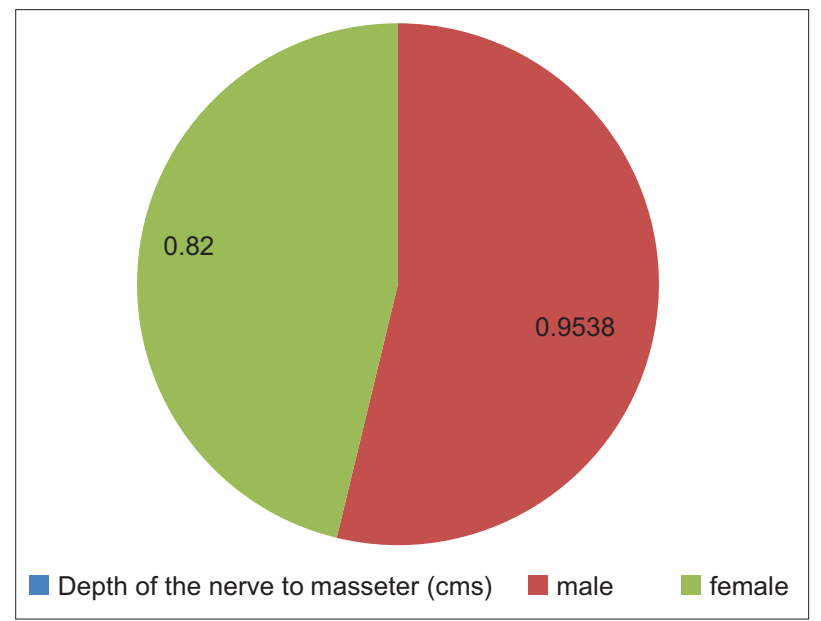

Figure 7: Gender-based comparison of depth of masseteric nerve. (Created with Microsoft Office Excel 2007) was encountered. This fascia was having a definite membranous part over the parotid gland but became very loose and fatty, towards the masseter muscle. Careful dissection was carried out in fatty layer of this fascia to expose the zygomatic branch of Facial nerve. This nerve was exposed distally up to the zygomatic arch and proximally at anterior border of the parotid gland. During exposure and identification of the zygomatic branch of facial nerve, its course was given much importance, since the upper buccal branch of the facial nerve lies very close to this zygomatic branch and at times they might arise as a common trunk. Immediately in front of the zygomatic branch of facial nerve, the superficial fascia was further dissected out and the tendinous part of superficial fibres of the masseter muscle was exposed. Their direction was downwards and backwards. Blunt dissection was carried out along anterior margin of this superficial tendon within a small circular aperture of diameter $2 \mathrm{~cm}$ to expose the intermediate layer of masseter muscle and their directions were noted to be downwards and forwards.

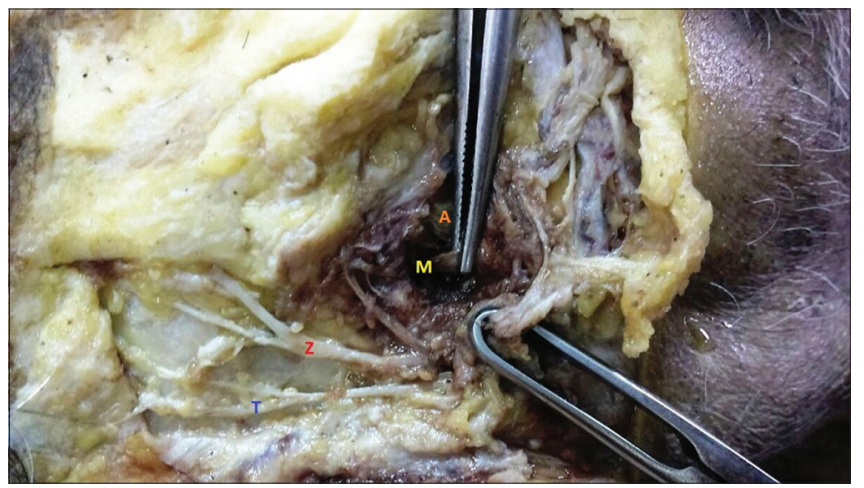

Figure 6: Predisposition of masseteric nerve and zygomatic branch of Facial nerve - a scope for tension free coaptation A - Tendon of masseter muscle $M$ - Masseteric nerve Z - Zygomatic branch of Facial nerve T - Temporal branch of facial nerve

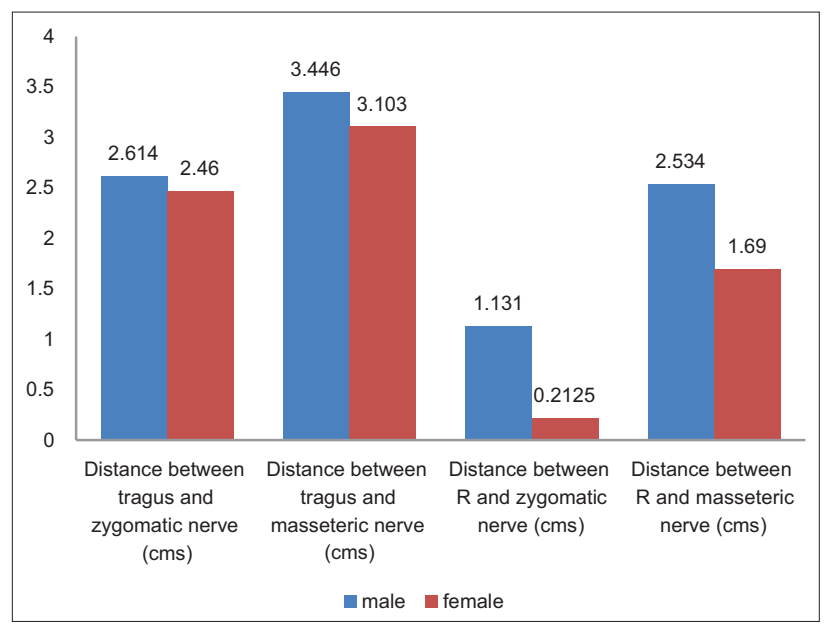

Figure 8: Gender-wise comparison of the locations of zygomatic branch of facial nerve and masseteric nerve in transverse and coronal planes. (Created with Microsoft Office Excel 2007) 
Dissection was continued to still deeper aspect of the masseter muscle and the nerve to masseter was localised at the plane between deep and intermediate muscle layers. For convenient localisation, the masseteric nerve was searched for, along the direction of intermediate muscle fibres, i.e., downwards and medially. Once the dissection and localisation of concerned nerves were over, a reference point $(R)$ was considered at the midpoint of a line joining outer canthus of eye and tragus of same side [Figure 3]. Using a copper wire $(0.1 \mathrm{~mm}$ diameter $)$ and slide callipers the distances of both nerves were noted from the above mentioned reference point, along the coronal plane. Similar measurements were taken from the tragus along a horizontal plane. From the superficial surface of masseter muscle, the depth of this nerve to masseter was also determined, using the same measuring tools. For this purpose, we have chosen the midpoint of the posterior border of the superficial layer of the masseter to be the upper point while the deeper point was taken on the masseteric nerve at its point of immergence in the hitherto defined operative field. An incidental finding was presence of a blood vessel across the subzygomatic part of face, between the zyomatic branch of Facial nerve and parotid duct. The vessel was of very small calibre and inconstant one, which was seen in altogether 3 sides (bilaterally in one cadaver and unilaterally in another). When traced along its course the vessel was found to be the superior branch of the transverse facial artery. ${ }^{[9]}$ The presence of this artery in the field of localising masseteric nerve should be kept in mind.

\section{RESULTS}

In this study, 8 male (16 sides) and 4 female ( 8 sides) cadavers were dissected. All were in the age group of 30 60 years. The mean distance of the zygomatic branch of Facial nerve from the tragus was $2.6 \mathrm{~cm}( \pm 0.5 \mathrm{~cm})$ and 2.5 $\mathrm{cm}( \pm 0.1 \mathrm{~cm})$ in male and female cadavers, respectively, along the horizontal plane. The nerve to masseter was $3.4 \mathrm{~cm}( \pm 0.4 \mathrm{~cm})$ and $3.1 \mathrm{~cm}( \pm 0.1 \mathrm{~cm})$ away from the tragus, in case of male and female cadavers, respectively, along the same horizontal plane. The reference point $(R)$ was found to coincide with the most prominent point of zygomatic arch (Zygoma), on surface projection, in 15 of the dissected cases (62.5\%). Zygomatic branch of the Facial nerve was located within a small circular area having radius $1 \mathrm{~cm}$, the centre of which lies at a distance of $1.1 \mathrm{~cm}( \pm 0.4 \mathrm{~cm})$ in males and $0.2 \mathrm{~cm}( \pm 0.1 \mathrm{~cm})$ in females from the point, ' $R$ ', in a vertical (coronal) plane. The nerve to masseter was found within a circular area having $1 \mathrm{~cm}$ radius, the centre of which was at a distance of $2.5 \mathrm{~cm}( \pm 0.4 \mathrm{~cm})$ and $1.7 \mathrm{~cm}( \pm 0.2 \mathrm{~cm})$ from $R$, in male and female cadavers, respectively [Figures 4 and 5]. These measurements were taken along a coronal plane. Finally, the depth of masseteric nerve, from the surface of masseter muscle was measured and seen to be $1 \mathrm{~cm}( \pm 0.1 \mathrm{~cm})$ and $0.8 \mathrm{~cm}( \pm 0.1 \mathrm{~cm})$, in male and female cadavers, respectively [Figure 6]. The plane of masseteric nerve was between intermediate and deep layers of the muscle. In this study, there happens to be a definite statistically significant sexual dimorphism in the situation of these nerves from the reference points [Figures 7 and 8]. A branch of the transverse facial artery was noted in the depth of loose areolar tissue (presumably a part of parotidomasseteric fascia) in only 3 sides (out of 24 sides studied), between the zygomatic branch of facial nerve and the parotid duct. This artery might come in operative field, though it is an inconstant branch of the transverse facial artery.

\section{DISCUSSION}

Facial nerve paralysis is a condition having various signs and symptoms. Loss of facial expression is conspicuous by its absence. Over the years, several surgical approaches have been devised for overcoming this problem. The chief aim of reconstructive surgery is restoration of facial symmetry and smile reanimation along with functional rehabilitation of the facial sphincters. When direct nerve repair is not possible due to either non-availability of the proximal segment or in congenital idiopathic facial palsy, nerve grafting is the current surgical method of choice. Currently, the hypoglossal-facial ${ }^{[10]}$ technique is commonly undertaken for smile restoration surgeries. to avoid the hypoglossal facial nerve transfer related complications such as haemilingual atrophy, facial hypertonia and facial synkinesis, alternative motor donors have been searched. The nerve to masseter, which is a motor branch of the Trigeminal nerve have been used as a motor nerve donor for ipsilateral facial palsy with encouraging results. Our aim has been to delineate the specific anatomical locations of this nerve with respect to the surrounding soft tissues and bony landmarks. Several anatomical studies in the past have outlined the branching patterns of the masseteric nerve from the mandibular notch up to its terminal arborisations within the masseter. ${ }^{[1]]}$ The main difficulty with the direct neurotisation approach is the relative steep learning curve for the trainee surgeons. 
Cotrufo et al..$^{[12]}$ have studied the topographical anatomy of the masseteric nerve, whereby, they have identified a masseteric area with respect to the zygomatic notch and the base of the tragus. In this study, we have tried to approach the problem from the point of view of a surgeon who needs to precisely locate the nerve in minimum amount of time. Hence, we defined a soft tissue point ' $R$ ' with respect to the outer canthus and the tragus and then located the zygomatic and masseteric nerves with the help of these two points. This approach shrinks the area of muscle tissue dissection to such a small area that, muscle fibre loss and post-operative tissue scarring can be minimised to a great extent. One thing needs to be mentioned here that, the skin incision used for this study is based on cadavers only for easier anatomical localisation of the nerves and does not contradict the standard surgical incisions used by plastic surgeons during facial surgeries in patients. Another difficulty with the neurotisation approach is to specifically locate the intramuscular location of the masseteric nerve. The masseter muscle being a muscle disposed in three layers poses serious difficulties in nerve location. It has been known for long that the masseteric nerve lies in between the intermediate and the deep layers of the muscle, but pre-operative location is difficult. Hence, we tried to locate the precise depth of the nerve in both sexes from the surface of the masseter. This problem has not been approached in this fashion ever before. With the help of the findings of this study, a surgeon can now easily locate the zygomatic and masseteric nerves with the help of a unique soft tissue reference point as well as locate the depth at which the nerve to masseter can be found. Not only that, our study aims to alert the surgeon about the possibility of encountering a branch of the transverse facial artery in the operative field. As a corollary to this dissection, we noted that if the muscle fibres are dissected immediately anterior to the tendons of the superficial layer masseter the masseteric nerve can be approached very easily. Hence, this study is unique in not only defining numerical values with respect to soft tissues but also defines the specific plane of dissection such that the masseteric nerve is approached most easily. In the course of our study, we have shown the proximity of the zygomatic and the masseteric nerves which can be easily approximated in an end to end fashion, which has been found superior, in comparison to the end to side approach. ${ }^{[13]}$ The study also points out the possibility of tension-free anastomosis between these two nerves, as a sufficient length of the donor and recipient nerves can be mobilised in a small dissection window, which is a prerequisite for adequate neurotisation to occur. The reference point ' $R$ ' can be considered as a new surface point, denoting the exact location of Zygoma, which can be used as a standard surface marking landmark for further facial studies.

\section{Financial support and sponsorship}

Nil.

\section{Conflicts of interest}

There are no conflicts of interest.

\section{REFERENCES}

1. Cha Cl, Hong CK, Park MS, Yeo SG. Comparison of facial nerve paralysis in adults and children. Yonsei Med J 2008;49:725-34.

2. Javeed Ahmad S, Hamid Rather A. Prospective study of physical therapy in facial nerve paralysis: Experience at a multispeciality hospital of Kashmir. J Med Sci 2012;15:145-8.

3. Mehta RP. Surgical treatment of facial paralysis. Clin Exp Otorhinolaryngol 2009;2:1-5.

4. O'Brien BM, Franklin JD, Morrison WA. Cross-facial nerve grafts and microneurovascular free muscle transfer for long established facial palsy. Br J Plast Surg 1980;33:202-15.

5. Terzis JK, Konofaos P. Nerve transfers in facial palsy. Facial Plast Surg 2008;24:177-93.

6. Hirsh LF, Murtagh F. Spinofacial anastomosis. Acta Neurochir (Wien) 1978;40:285-97.

7. Audolfsson T, Rodríguez-Lorenzo A, Wong C, Cheng A, Kildal M, Nowinski D, et al. Nerve transfers for facial transplantation: A cadaveric study for motor and sensory restoration. Plast Reconstr Surg 2013;131:1231-40.

8. Collar RM, Byrne PJ, Boahene KD. The subzygomatic triangle: Rapid, minimally invasive identification of the masseteric nerve for facial reanimation. Plast Reconstr Surg 2013;132:183-8.

9. Yang HJ, Gil YC, Lee HY. Topographical anatomy of the transverse facial artery. Clin Anat 2010;23:168-78.

10. Bermudez LE, Nieto LE. Masseteric-facial nerve anastomosis: Case report. J Reconstr Microsurg 2004;20:25-30.

11. Brenner E, Schoeller T. Masseteric nerve: A possible donor for facial nerve anastomosis? Clin Anat 1998;11:396-400.

12. Cotrufo S, Hart A, Payne AP, Sjogren A, Lorenzo A, Morley S. Topographic anatomy of the nerve to masseter: An anatomical and clinical study. J Plast Reconstr Aesthet Surg 2011;64:1424-9.

13. Mathes SJ. Plastic Surgery: General Principles. $2^{\text {nd }}$ ed., Vol. I. Ch. 25. Philadelphia: Saunders; 2006. p. 733. 